Paper

\title{
Characterization of three cell lines established from medaka embryos
}

\section{メダカ胚より樹立した細胞株の解析}

\author{
Yasuo ISHIKAWA, Rie ISHII, Sumitsuna HATAKEYAMA, Masashi KASAI and \\ Masao HYODO \\ Department of Biological Science and Technology, Tokai University, 317 Nishino, Numazu, 410-0395, \\ Japan TEL: +81-55-968-1111 FAX: +81-55-968-1156 e-mail: hyodo@tokai.ac.jp
}

( Received 24, March 2008 Accepted 23, May 2008 )

\begin{abstract}
We established three cell lines from medaka embryos. In the present study, we investigated the optimal conditions for growth of these cells with regard to the basal culture medium and concentration of fetal bovine serum (FBS). The best cell growth for all three cell lines was achieved with a 1:1 mixture of L15 medium and 199 medium with a relatively high concentration (20\%) of FBS. The growth curves for the cell lines revealed that their doubling times ranged from 48 to $93 \mathrm{~h}$. We also analyzed the numbers of chromosomes in the cell lines and found that their numbers varied from near-diploid to hyper-tetraploid. The results of the present study should be helpful for research in fish cell culture.
\end{abstract}

Key words : Medaka, cell culture, growth conditions, chromosome number

\section{INTRODUCTION}

Small fresh-water fish such as the medaka (Oryzias latipes) and zebrafish (Danio rerio) are important animal models for research in many fields of biology. Medaka can be maintained easily in the laboratory and have a short generation time of about 3 months. Many eggs are obtained daily, and these eggs are relatively large (about $1 \mathrm{~mm}$ in diameter) and transparent, making it easy to observe or manipulate them under a low-magnification microscope. Thus, medaka are useful experimental animals. Many cell lines have been established from several fish species, including the medaka, and are utilized in various fields of research. ${ }^{1,2}$

Mammalian pluripotent embryonic stem (ES) cell lines have been established from the inner cell masses of blastocysts. These cell lines provide an experimental system for genetic manipulations that create transgenic animals. In addition, these cell lines are expected to be useful for tissue engineering by producing specifically differentiated cells during in vitro cultures. Although attempts to obtain such ES cells from fish embryos have been reported, ${ }^{3,4}$ success remains limited at present. To advance the technology for fish cell culture, additional information about the optimal culture conditions is indispensable. We previously established three cell lines from medaka embryos in our laboratory. However, we did not analyze the best growth conditions or characterize these cells in detail. To clarify the optimal conditions for culture of these fish cell lines, we focused on the basal culture medium, concentration of FBS and growth rate. We also investigated the chromosome numbers in these cells.

\section{METHODS AND MATERIALS}

\section{II-A. Cell culture}

The three medaka cell lines (MR-1, MIC-3 and Mib) used in this study were established in our laboratory. The MR-1 cell line was derived from 5-day-old embryos, while the MIC-3 and Mib cell lines were derived from blastula-stage embryos. Fertilized eggs were sterilized in a neutralized $0.4 \% \mathrm{NaClO}$ solution for $1 \mathrm{~min}$, immersed in $70 \%$ ethanol for $10 \mathrm{~s}$ and then washed in a sterile medaka saline solution $\left(0.75 \% \mathrm{NaCl}, 0.02 \% \mathrm{KCl}, 0.02 \% \mathrm{CaCl}_{2}, 0.02 \%\right.$ 
$\left.\mathrm{NaHCO}_{3}\right)^{5}$ containing $100 \mu \mathrm{g} / \mathrm{ml}$ of ampicillin and 50 $\mu \mathrm{g} / \mathrm{ml}$ of streptomycin. The embryos were removed from the eggs and dissected into small pieces using a pair of fine scissors. The cells were dissociated by using a trypsin solution ( $0.1 \%$ trypsin and $0.05 \%$ EDTA in phosphate-buffered saline) or by simply pipetting in case of the blastula-stage embryos. The dissociated cells were incubated in culture flasks ( 25 $\mathrm{cm}^{2}$; NUNC) containing $5 \mathrm{ml}$ of 199 medium supplemented with $15 \%$ fetal bovine serum (FBS; HyClone Lab. Inc.). The incubation temperature was set at $28^{\circ} \mathrm{C}$ since the cells were found to grow well at this temperature. The cells were serially transferred every 8-10 days at split ratios of $1: 2$ to $1: 5$ and continuously cultured for more than 5 years.

\section{II-B. Culture media}

In the present study, four basal media (199, DMEM, F12 and L15) were used for cell culture. Medium 199 was originally developed by Morgan et al. $(1950)^{6}$ for culturing chick embryo fibroblasts, but is now used for culturing a wide variety of cells, including mammalian cells. DMEM (or DME; Dulbecco's modified Eagle's medium) is a modified version of Eagle's medium (Eagle 1955) ${ }^{7}$ created by Dulbecco and Freeman $(1959)^{8}$ to achieve high-density growth of cultured human or hamster cells. In contrast to these media, F12 was designed by Ham $(1965)^{9}$ for clonal growth of low-density hamster cells. These three media were purchased from Nissui Seiyaku Co. L15 medium was developed by Leibovitz $(1963)^{10}$ and contains galactose and Na-pyruvate instead of glucose. L15 medium was purchased from COSMO Bio Co. All the basal media were prepared in $20 \mathrm{mM}$ HEPES (pH 7.3) with $1.7 \mathrm{~g} / 1 \mathrm{NaHCO}_{3}$.

\section{II-C Analysis of cell growth}

For analysis of cell growth, aliquots containing $3 \times 10^{5}$ cells were plated in culture flasks $\left(25 \mathrm{~cm}^{2}\right)$ and incubated for 8 days. After the incubation, the cells were dissociated into single cells with a trypsin solution and the cell numbers were determined using a Coulter counter (Beckman Coulter Inc.).

\section{II-D. Karyotype analysis}

For determination of the numbers of chromosomes, log-phase cells were treated with $50 \mathrm{ng} / \mathrm{ml}$ of colcemid for $8 \mathrm{~h}$. The cells were then collected, incubated in $75 \mathrm{mM} \mathrm{KCl}$ at $37^{\circ} \mathrm{C}$ for $10 \mathrm{~min}$ and then fixed in acetic acid-ethanol (1:3) for $30 \mathrm{~min}$ at room temperature. The cells were collected by centrifugation, suspended in a small volume of the fixative and applied to a glass slide. The glass slide was flamed to achieve better spreading of the mitotic cells. The cells were stained with Giemsa's solution (MERCK Ltd.). Metaphase cells were photographed and recorded using a micrographic digital camera.

\section{RESULTS AND DISCUSSION}

The cell lines used in this study were originally established using 199 medium supplemented with $15 \%$ FBS and serially transferred under the same conditions. During the extended period of cell culture, the growth rates did not alter and we never experienced senescence of the cells. Thus, these cells were considered to be immortal. In general, fish cells are known to be immortal, ${ }^{1,11,12}$ unlike normal mammalian somatic cells that usually show senescence over about 50 cell generations. ${ }^{13}$ Fig. 1 shows the morphologies of the cells used in this study. All three cell lines showed fibroblastic or spindle-shaped appearances.

First, we compared the cell growth rates in four basal media (199, DMEM, F12 and L15) to find out the optimal medium for these cell lines. All the culture media were supplemented with $15 \%$ FBS. In each flask, $3 \times 10^{5}$ cells were plated in $5 \mathrm{ml}$ of culture medium and incubated for 8 days. The results are shown in Fig. 2. The growth rates of the cells varied among the cell line. For this reason, the highest yield of cells for each cell line was indicated as $100 \%$ and the relative cell numbers are shown in Fig. 2. When each basal medium was used independently, L15 gave the best or second-best results for all three cell lines. Fig. 2 also shows that the effectiveness of each culture medium differed among the cell lines. For example, Mib cells showed relatively slow growth in F12 medium compared to the other two cell lines. We expected that 199 medium would give the best results since all the cell lines were established and maintained in this medium as mentioned above. During the long-term culture, cells that grew well in 
199 medium may have been selected in the cell population while those cells that did not show suitable growth may have been eliminated. However, the results indicated that 199 medium was not the best medium for all three cell lines. Thus, we tried a 1:1 mixture of L15 medium and 199 medium. The results showed that this mixture gave the best cell growth rates (indicated as $100 \%$ in Fig.2).

Next, we analyzed the serum concentrations (1$20 \%$ ) added to the culture medium. Collodi et al. $(1992)^{14}$ reported that $10 \%$ FBS was inhibitory for growth of cells derived from zebrafish embryos. For this reason, they used 1\% FBS together with trout serum and an embryo extract. As shown in Fig. 3, the growth rates of all three medaka cells were dependent on FBS, and 20\% FBS was the best

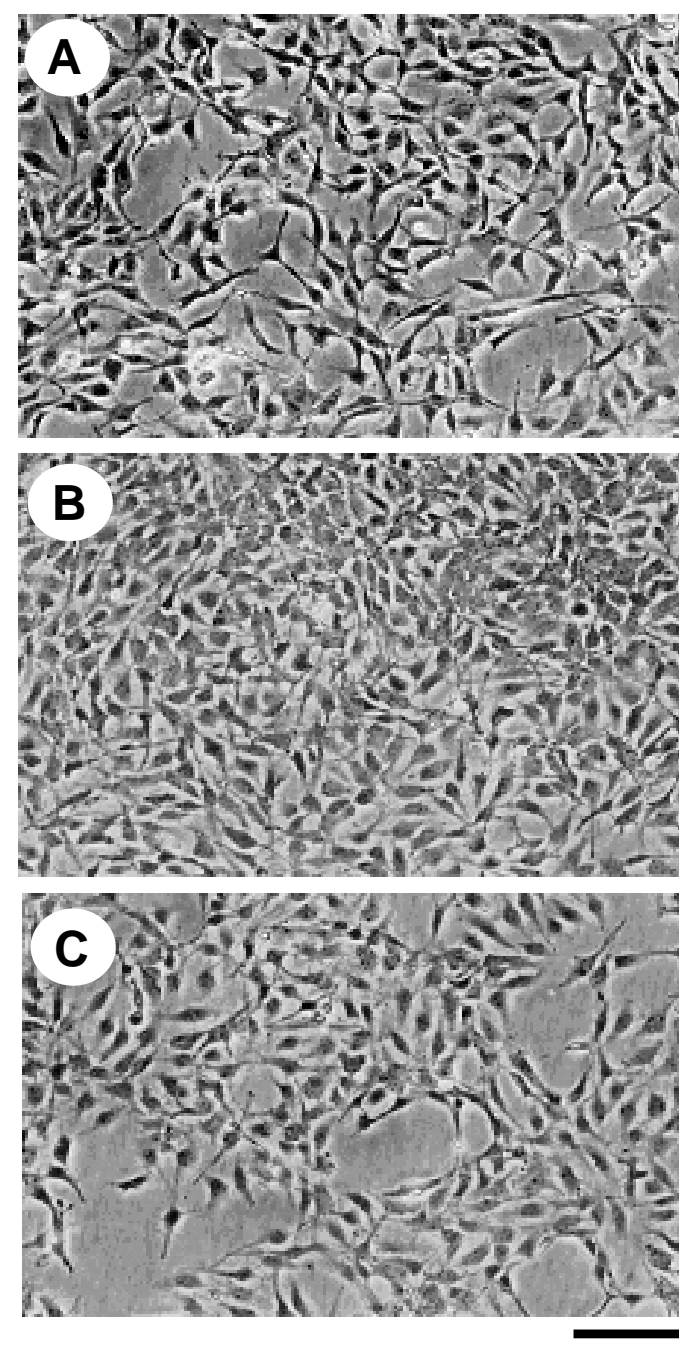

Fig. 1. Morphology of the cultured medaka embryo cells. A; MR-1. B; MIC-3. C; Mib. Bar $=100 \mu \mathrm{m}$. concentration for growth. These findings may also be interpreted as a result of the cells having been selected to grow in the presence of FBS over a long

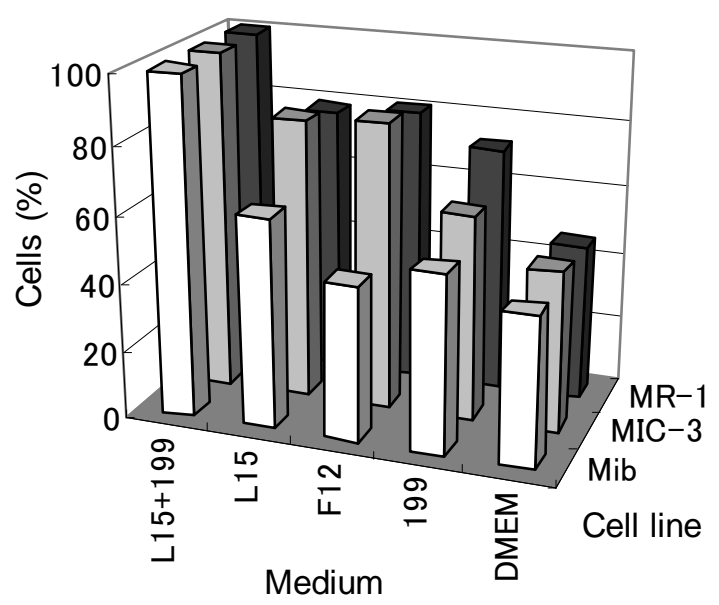

Fig. 2. Growth rates of the three cell lines in different basal media.

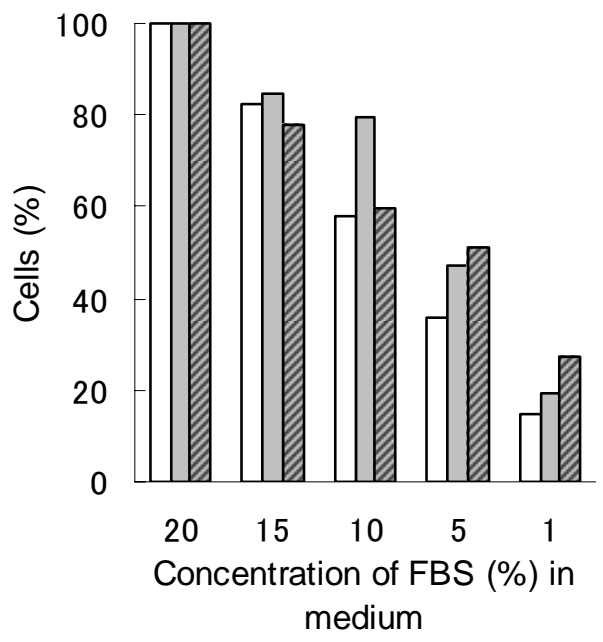

Fig. 3. Growth rates of the three cell lines in different FBS concentrations. Open column; MR-1 cell, gray column; MIC-3 cells and hatched column; Mib cells.

period of time. However, our preliminary study showed that the growth of cells in primary cultures starting from early-stage embryos was also strongly dependent on FBS (data not shown), suggesting that FBS is an essential factor for growth of these cells.

The growth rates of the three cell lines were determined. In this study, a 1:1 mixture of L15 medium and 199 medium was used as the culture 
medium and supplemented with $15 \%$ FBS. As shown in Fig. 4, the growth rates differed among the cell lines. The doubling time of MR-1 cells, which exhibited the fastest growth among the cell lines, was about $48 \mathrm{~h}$. The doubling time of Mib cells was $62 \mathrm{~h}$, while that of MIC- 3 cells was $93 \mathrm{~h}$. Fig. 4 also shows that the cells continued to grow for 15 or more days.

We analyzed the chromosome numbers in the three cell lines. The normal chromosome number of medaka somatic cells is $48 .{ }^{15}$ As shown in Fig. 5, the numbers of chromosomes were quite variable among the cell lines. The modal peak was found to be near-tetraploid (90-99) in the MR-1 (Fig. 5A) and MIC-3 (Fig. 5C) cell lines. However, in both cell lines, there were considerable numbers of cells containing more than 100 chromosomes. There were two peaks in the case of Mib cells (Fig. 5B), one at near-diploid (40-49) and the other in the range of 60-69. This cell line also contained cells with

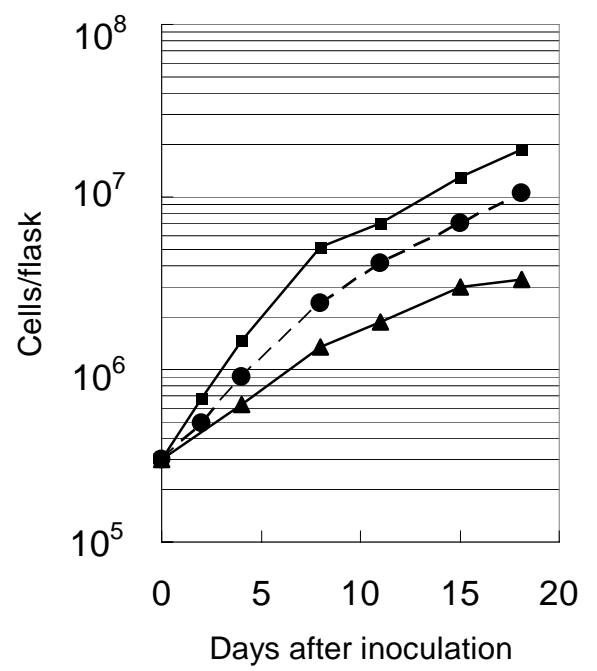

Fig. 4. Growth curves of the three cell lines cultured at $28^{\circ} \mathrm{C}$. $\mathbf{m}$; MR-1 cells. $\bullet$; Mib cells. $\boldsymbol{\Delta}$; MIC-3 cells.

tetraploid or more chromosomes. These results indicate that the chromosome numbers in the medaka cells were not stable and changed during serial transfer over a long time. These results will help to establish new cell lines, and possibly ES cell lines, or to understand the nature of cultured medaka cells.
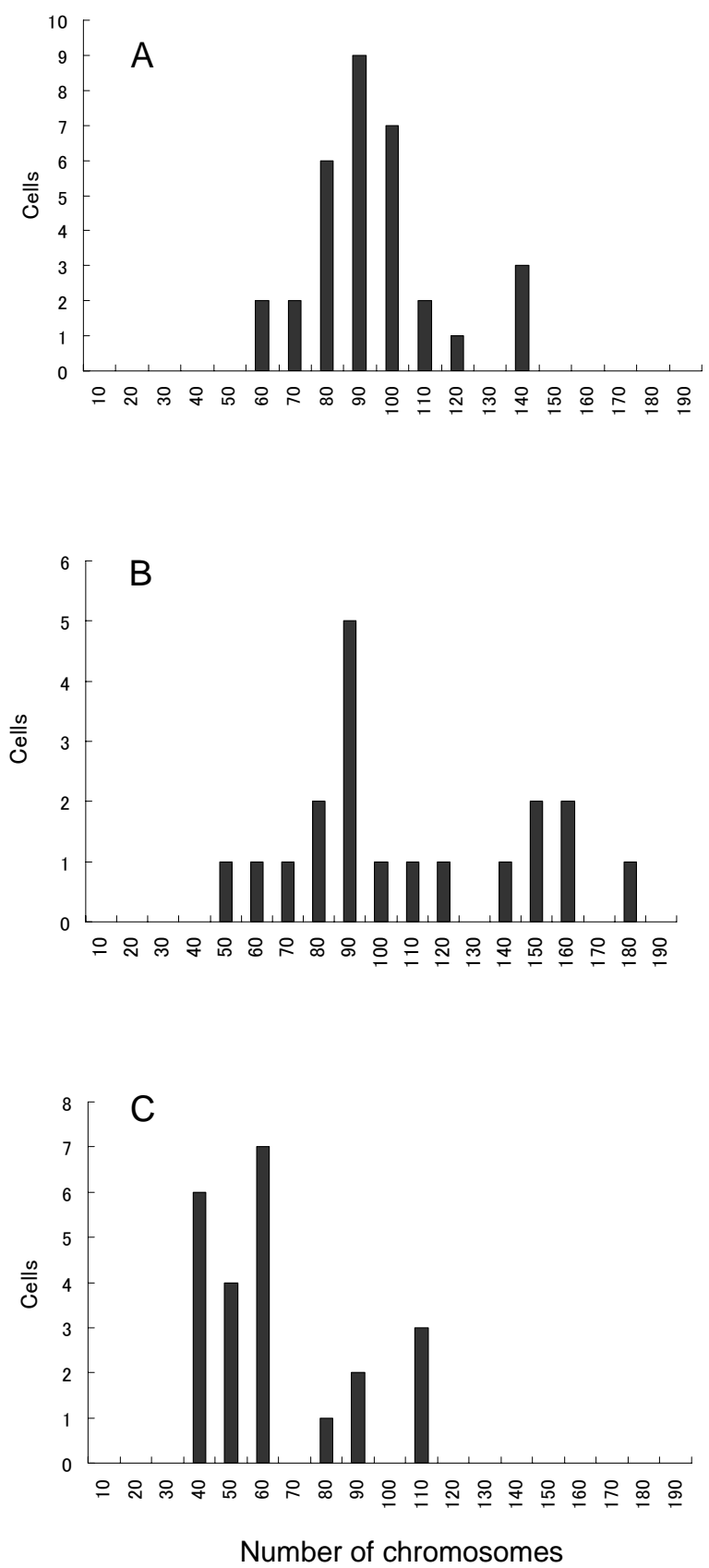

Fig.5 Frequency distribution of chromosomes of the cultured cells. A; MR-1 cells, B; MIC-3 cells, C;

Mib cells.

\section{REFERENCES}

${ }^{1}$ Nicholson, B. L. (1989). Fish cell culture: an update. Adv. Cell Culture 7:1-18. 
2 Wolf, K. and Mann, J. A. (1980). Poikilotherm vertebrate cell lines and viruses: A current listing for fishes.InVitro 16:168-179.

${ }^{3}$ Hong, Y., Winkler, C. M. and Schartl, M. (1998). Efficiency of cell culture derivation from blastula embryos and of chimera formation in the medaka (Oryzias latipes) depends on donor genotype and passage number. Dev. Genes Evol. 208:595-602.

${ }^{4}$ Fan, L. and Collodi, P. (2006). Zebrafish embryonic stem cells. Methods Enzymol. 418:64-77.

${ }^{5}$ Yamamoto, T. (1961). Physiology of fertilization in fish eggs. Int. Rev. Cytol. 12:361-405.

${ }^{6}$ Morgan, J. F., Morton, H. J. and Parker R. C. (1950). Nutrition of animal cells in tissue culture. I. Initial studies on a synthetic medium. Proc. Soc. Exp. Biol. Med. 73:1-8.

${ }^{7}$ Eagle, H. (1955). Nutrition needs of mammalian cells in tissue culture. Science 122:501-504.

${ }^{8}$ Dulbecco, R. and Freeman, G. (1959). Plaque production by the polyoma virus. Virology 8:396-407.

${ }^{9}$ Ham,R. (1965). Clonal growth of mammalian cells in a chemically defined synthetic medium. Proc. Natl. Acad. Sci. USA 53:288-293.

${ }^{10}$ Leibovitz, A. (1963). The growth and maintenance of tissue-cell cultures in free gas exchange with the atmosphere. Am. J. Hyg. 78, 173-180.

${ }^{11}$ Barkera, K.S., Quinioua S. M. A, Wilsona, M. R., Bengtena, E., Stugea, T. B., Warrb, G. W., Clema, L. W. and Miller, N. W. (2000). Telomerase expression and telomere length in immortal leukocyte lines from channel catfish. Dev Comp. Immun. 24:583-595.

${ }^{12}$ Klapper, W., Heidorn, K., Kuëhne,, K., Parwaresch, R. and Krupp G. (1998). Telomerase activity in 'immortal' fish. FEBS Letters 434:409-412.

${ }^{13}$ Hayflick, L. (1965). The limited in vitro lifetime of human diploid cell strains. Exp. Cell Res. 37:614-636.

${ }^{14}$ Collodi, P., Kamei, Y., Ernst, T., Miranda, C., Buhler, D. R., and Barnes, D. W. (1992). Culture of cells from zebrafish (Brachydanio rerio) embryo and adult tissues. Cell Biol. Toxicol. 8:43-61.

15 Iwamatsu, T. (1993). In The Biology of the Medaka, edited by Iwamatsu, T. (Scientist-Sha), p. 273 . 